\title{
応答曲面を利用した信頼性に基づく大域的最適化
}

伊藤 誠*1, 北山 哲士*2

\section{Reliability-based global optimization using response surface}

\author{
Makoto ITO*1 and Satoshi KITAYAMA*2 \\ ${ }^{* 1}$ Institute of Science and Engineering, Kanazawa University \\ Kakumamachi, Kanazawa-shi, Ishikawa 920-1192, Japan \\ ${ }^{* 2}$ Advanced Manufacturing Technology Institute, Kanazawa University \\ Kakumamachi, Kanazawa-shi, Ishikawa 920-1192, Japan
}

Received: 18 December 2020; Revised: 13 April 2021; Accepted: 10 May 2021

\begin{abstract}
Reliability-based design optimization (RBDO) is one of design optimization techniques considering uncertainty and has gained attention in the engineering design. To reduce the number of function evaluations in the RBDO, many studies using response surface have been conducted. It has been recognized that sampling strategy plays an important role for highly accurate reliability analysis as well as the reduction of function evaluations. In this paper, reliability-based global optimization with a novel sampling strategy is proposed. The proposed sampling strategy consists of two parts. In the first sampling strategy, several sampling points are added around unexplored region in order to achieve the uniform distribution of the sampling points. Second sampling strategy adds a new sampling point at one of Most Probable Target Points (MPTPs) for improving the local accuracy, in which the new sampling point is selected by the distribution of sampling points. In addition, a deterministic formulation of the RBDO is conducted to search global optimal solution efficiently. Through numerical examples, the validity of the proposed method is examined.
\end{abstract}

Keywords : Reliability-based design optimization, Engineering optimization, Optimum design, Response surface,

Radial basis function network

\section{1. 緒言}

信頼性に基づく最適設計（Reliability-Based Design Optimization: RBDO）とは，不確定性（ばらつき）の影響を 考慮する最適設計法である（Choi et al., 2007）。この最適設計法の特徵は，確率変数を用いて不確定性をモデル化 し，破損確率（制約を違反する確率）を定量的に評価する点にあり，破損によって構造システム全体への影響が 大きいと考えられる構造物の設計，例えば自動車側面の而衝撃設計（Youn et al., 2004）やタービンブレードの而 疲労設計（Hu et al., 2016） に適用されている. 図 1 に示すように，信頼性に基づく最適設計は，最適解の探索と 同時に繰り返し計算による破損確率の評価をする二重ループであるため，不確定性を考慮しない確定的な最適設 計法と比べて関数評価回数が多くなるとされる．特に，衝突解析のようなシミュレーションに長い計算時間を要 する設計問題を対象とする場合，少ないシミュレーション回数で最適解を得ることが重要となるため，関数を近 似する応答曲面を利用した最適設計法が用いられている.

No.20-00442 [DOI:10.1299/transjsme.20-00442], J-STAGE Advance Publication date : 18 May, 2021

*1 正員, 金沢大学 理工研究域（广920-1192 石川県金沢市角間町）

*2 正員，金沢大学 設計製造技術研究所（广920-1192 石川県金沢市角間町）

E-mail of corresponding author: m-ito@se.kanazawa-u.ac.jp 
応答曲面を利用した信頼性に基づく最適設計に関する研究では, 応答曲面の最適解や追加されたサンプル点の 情報から段階的に応答曲面の精度を高めて最適解を得る, 逐次近似最適化の考え方を利用するものが多い. 逐次 近似最適化ではサンプル点の追加方法が重要となるが，それは大きく二つに分類される.

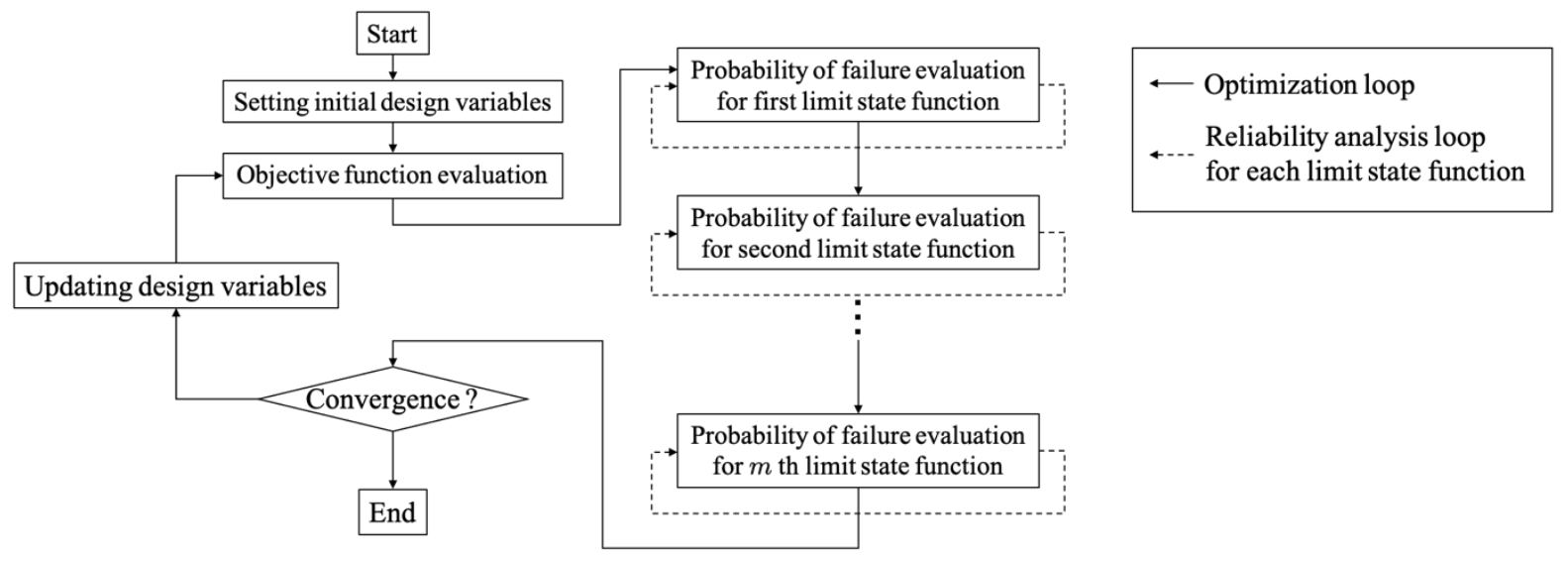

Fig. 1 General flow of RBDO.

一つ目は, 得られた最適解の周辺領域を対象に応答曲面を作成し, その領域内にサンプル点を追加する方法で ある．例えば，Youn and Choi は，標準正規空間上に Analysis window と呼ばれる領域を設定し，その領域内にサ ンプル点を追加している（Youn and Choi, 2004）。Ju and Lee は，Analysis window 内に Kriging を用いて応答曲面 を作成し，平均二乗誤差が最大となる点を追加寸る方法を提案している (Ju and Lee, 2008)。他にも, 目標の信頼 性指標を半径とする超球面上に追加する方法 (Zhuang and Pan, 2012) や. Kriging を用いて MPP (Most Probable Point）と呼ばれる点を探索し，その点を追加する方法（Li et al., 2016）などがある. これらは，局所的な応答曲面 の近似精度を向上させて，破損確率を高い精度で評価することを狙う点に特徵がある.

二つ目は, 限界状態（破損領域と安全領域の境界）上の点をサンプル点として追加する方法であり, MCMC (Markov Chain Monte Carlo simulation) を利用した方法（Dubourg et al., 2011）や，Kriging による指標関数を用いて 限界状態上の点を追加する方法 (Lee and Jung, 2008), 目的関数值を考慮した指標関数で最適解に近い限界状態上 にサンプル点を集中させる方法（Chen et al., 2014, Chen et al., 2015）などがある．これらは，限界状態上にサンプ ル点を集中させて近似精度を向上させることで, 破損確率を高い精度で評価することを狙う点に特徽がある.

応答曲面を利用して最適解を得る場合, なるべく少ないサンプル数で大域的最適解が得られることが望ましい と考えられる．特に，大域的最適解を得るためには，サンプル点の疎密をなるべく減らして大域的な様相を把握 することが重要と思われる (Jones et al., 1998). しかし, 上述した先行研究では, 局所的な領域や限界状態上にサ ンプル点が集中することが想定されるため, 大域的最適解が得られるかは明らかでない.また，非線形性の高い 関数の大域的最適解を得るためには，多点同時探索を用いることが望ましいと考えられる．しかし，関数評価回 数が多い信頼性に基づく最適設計では，効率的に大域的最適解を探索できるとは言い難い.

ここで，信頼性に基づく最適設計において，大域的最適解を得るために解決すべき課題をまとめると以下のよ うになる。

課題 1: 局所的な近似精度の向上を図りつつ, 大域的な様相を把握できるような新たなサンプル点の配置方法. 課題 2: 多点同時探索による大域的最適解の探索を効率的に行うためにアルゴリズムを改良すること.

そこで本研究では，応答曲面を用いた信頼性に基づく大域的最適化手法を提案する. 課題 1 に対して, 局所的 な近似精度向上を狙いつつ, サンプル点が一様に分布するようなサンプル点追加アルゴリズムを提案する. 課題 2 に対して, 信頼性に基づく最適設計問題を確定的な最適設計問題に変換し, 破損確率の繰り返し評価を行わな い単一ループ法とする. なお, 応答曲面には，RBF（Radial Basis Function）ネットワークを用いる. 以下，第2 章 において信頼性に基づく最適設計を簡単に説明し，第 3 章において本研究で利用する RBF ネットワークを利用 した応答曲面作成方法について述べる. 第 4 章において提案する手法について説明し，数值計算例を通じてその 有効性を検討寸る. 


\section{2. 信頼性に基づく最適設計}

信頼性に基づく最適設計問題では，不確定性を確率変数としてモデル化し，その期待值を設計変数とする.つ まり，制約を違反する確率が規定值以下となる条件のもとで，目的関数を最小化する期待值を探索する問題とし て次のように定式化される.

Minimize: $f(\boldsymbol{d})$

subject to: $P\left[g_{j}(\boldsymbol{x}) \leq 0\right] \leq \Phi\left(-\beta_{j}^{\text {Tar }}\right) \quad(j=1, \cdots, m)$

$$
d_{i}^{L} \leq d_{i} \leq d_{i}^{U} \quad(i=1, \cdots, n)
$$

ただし， $\boldsymbol{d}=\left(d_{1}, \cdots, d_{n}\right)^{T}$ は設計変数べクトルで，その下限值，上限值をそれぞれ $d_{i}^{L}, d_{i}^{U}(i=1, \cdots, n)$ とする. また, $\boldsymbol{x}=\left(x_{1}, \cdots, x_{n}\right)^{T}$ は確率変数ベクトルを表す. $f(\cdot), g_{j}(\cdot)$ はそれぞれ目的関数と $j$ 番目の限界状態関数であ る. 限界状態関数とは，破損条件を以下のように定義する関数である.

$$
g_{j}(\boldsymbol{x})\left\{\begin{array}{cc}
>0 & (\text { safe }) \\
=0 & (\text { limit state }) \\
<0 & \text { (failure) }
\end{array} \quad(j=1, \cdots, m)\right.
$$

限界状態関数を用いた制約式(1b)を信頼性制約とよぶ．信頼性制約は，破損確率（限界状態関数が負になる確 率）を設計者が設定した目標の信頼性指標 $\beta_{j}^{\mathrm{Tar}}$ と正規累積分布関数 $\Phi(\cdot)$ を用いた所望の確率以下とするものであ る.ここで, 確率変数の結合確率密度関数を $f_{\boldsymbol{X}}(\boldsymbol{x})$ とすると, 破損確率は次のように求められる.

$$
P\left[g_{j}(\boldsymbol{x}) \leq 0\right]=\int_{\boldsymbol{x} \in g_{j}(\boldsymbol{x}) \leq 0} f_{\boldsymbol{X}}(\boldsymbol{x}) d \boldsymbol{x}(j=1, \cdots, m)
$$

式(3)は，解析的に解くことが困難であるとされているため（Choi et al., 2007), 確率変数が従う統計分布からサ ンプリングを行う MCS（Monte Carlo Simulation）や，限界状態関数をMPP まわりで線形近似する FORM（First Order Reliability Method）を用いて破損確率を評価する.

ここでは，FORM を用いて破損確率を評価する方法について説明する．まず，以下の式のように確率変数べク トル $\boldsymbol{x}$ を適当な関数 $T_{r}$ を用いて標準正規確率変数ベクトル $\boldsymbol{u}$ に変換する.

$$
\boldsymbol{u}=T_{r}(\boldsymbol{x})
$$

このとき, 設計変数ベクトルは確率変数ベクトルの期待值であることから, 以下の式が成り立つ.

$$
T_{r}(\boldsymbol{d})=\mathbf{0}
$$

なお， $\mathbf{0}=(0, \cdots, 0)^{T}$ である. また，標準正規空間に変換された限界状態関数を $g_{j}^{U}(\boldsymbol{u})(j=1, \cdots, m)$ とする.

ここで, $j$ 番目の限界状態関数 $g_{j}^{U}(\boldsymbol{u})$ を MPP まわりで線形近似することを考える. MPP とは, 限界状態 $g_{j}^{U}(\boldsymbol{u})=0$ 上の点の中で最も原点に近い点のことであり, 以下のように定義される.

$$
\boldsymbol{u}_{\mathrm{MPP}}^{(j)}=\arg \min _{g_{j}^{U}(\boldsymbol{u})=0}\|\boldsymbol{u}\|
$$

MPP まわりで限界状態関数を線形近似すると, $g_{j}^{U}\left(\boldsymbol{u}_{\mathrm{MPP}}^{(j)}\right)=0$ より，

$$
g_{j}^{U}(\boldsymbol{u}) \approx g_{j}^{U}\left(\boldsymbol{u}_{\mathrm{MPP}}^{(j)}\right)+\nabla^{T} g_{j}^{U}\left(\boldsymbol{u}_{\mathrm{MPP}}^{(j)}\right)\left(\boldsymbol{u}-\boldsymbol{u}_{\mathrm{MPP}}^{(j)}\right)=\nabla^{T} g_{j}^{U}\left(\boldsymbol{u}_{\mathrm{MPP}}^{(j)}\right)\left(\boldsymbol{u}-\boldsymbol{u}_{\mathrm{MPP}}^{(j)}\right)
$$

となり, 限界状態関数が標準正規確率変数の線形関数で表せる. よって, 限界状態関数の值は正規分布に従い, その平均 $\mu_{j}$ と分散 $\sigma_{j}^{2}$ は次のように求められる.

$$
\mu_{j}=-\nabla^{T} g_{j}^{U}\left(\boldsymbol{u}_{\mathrm{MPP}}^{(j)}\right) \cdot \boldsymbol{u}_{\mathrm{MPP}}^{(j)}
$$




$$
\sigma_{j}^{2}=\nabla^{T} g_{j}^{U}\left(\boldsymbol{u}_{\mathrm{MPP}}^{(j)}\right) \cdot \nabla g_{j}^{U}\left(\boldsymbol{u}_{\mathrm{MPP}}^{(j)}\right)=\left\|\nabla g_{j}^{U}\left(\boldsymbol{u}_{\mathrm{MPP}}^{(j)}\right)\right\|^{2}
$$

式(8)と式(9)を用いて限界状態関数の值を標準正規化して破損確率を表現すると，次のようになる.

$$
P\left[g_{j}^{U}(\boldsymbol{u}) \leq 0\right]=P\left[\frac{g_{j}^{U}(\boldsymbol{u})-\mu_{j}}{\sigma_{j}} \leq-\frac{\mu_{j}}{\sigma_{j}}\right]=\Phi\left(-\frac{\mu_{j}}{\sigma_{j}}\right)
$$

$\mu_{j} / \sigma_{j}$ は原点から MPP までの距離を表すことから，破損確率はこの距離 $\beta_{j}$ を用いて評価できる．これを信頼性 指標とよぶ.このことから， $j$ 番目の限界状態関数に対応する信頼性制約は次のように書き換えることができる.

$$
\begin{aligned}
& P\left[g_{j}(\boldsymbol{x}) \leq 0\right]=\Phi\left(-\beta_{j}\right) \leq \Phi\left(-\beta_{j}^{\mathrm{Tar}}\right) \\
& \text { where: } \beta_{j}=\left\|\boldsymbol{u}_{\mathrm{MPP}}^{(j)}\right\|
\end{aligned}
$$

なお，MPP が複数考えられる場合でも，原点からの距離 $\beta_{j}$ は同じ值であることから最適化結果に影響はない.

\section{RBF ネットワークを用いた応答曲面作成法}

RBF ネットワークとは，三層型のフィードフォワード型のニューラルネットワークである. 入力ベクトルを $\boldsymbol{X}=\left(X_{1}, \cdots, X_{n}\right)^{T}$ とすると, RBF ネットワークの応答值 $\hat{Y}$ は次のように表される.

$$
\hat{Y}=\sum_{k=1}^{n_{p}} w_{k} h_{k}(\boldsymbol{X})
$$

ただし, $w_{k}, h_{k}(\cdot)$ はそれぞれ $k$ 番目の重み係数と基底関数を表す. 本研究では, 式(13)に示すガウス基底関数を 用いる. また, 基底関数の中心を訓練データ $X_{k}\left(k=1, \cdots, n_{p}\right)$ と一致させ, 基底関数の数が訓練データ数 $n_{p}$ と等 しいものとする.

$$
h_{k}(\boldsymbol{X})=\exp \left(-\frac{\left(\boldsymbol{X}-\boldsymbol{X}_{k}\right)^{T}\left(\boldsymbol{X}-\boldsymbol{X}_{k}\right)}{r_{k}^{2}}\right)
$$

ここで，基底関数の半径值 $r_{k}$ は，著者の一人が提案した以下の式を用いて決定する（Kitayama et al., 2011）.

$$
r_{k}=\frac{d_{k, \max }}{\sqrt{n} \sqrt[n]{n_{p}^{-1}}}
$$

なお, 式(15)中の $d_{k, \max }$ は, $k$ 番目の訓練データからの最大距離を表す. RBF ネットワークの学習は, 重み係数 の逆行列演算に帰着され, 訓練データ $X_{k}$ に対応寸る教師データを $Y_{k}\left(k=1, \cdots, n_{p}\right)$ とすると以下のようになる.

$$
\begin{aligned}
& \boldsymbol{w}=\left(\boldsymbol{H}^{T} \boldsymbol{H}+\boldsymbol{\Lambda}\right)^{-1} \boldsymbol{H}^{T} \boldsymbol{Y} \\
& \text { where: } \boldsymbol{w}=\left(w_{1}, \cdots, w_{n_{p}}\right)^{T}, \\
& \qquad \begin{aligned}
\boldsymbol{Y} & =\left(Y_{1}, \cdots, Y_{n_{p}}\right)^{T}, \\
\boldsymbol{\Lambda} & =\lambda \boldsymbol{I}, \\
\boldsymbol{H} & =\left[\begin{array}{ccc}
h_{1}\left(\boldsymbol{X}_{1}\right) & \cdots & h_{n_{p}}\left(\boldsymbol{X}_{1}\right) \\
\vdots & \ddots & \vdots \\
h_{1}\left(\boldsymbol{X}_{n_{p}}\right) & \cdots & h_{n_{p}}\left(\boldsymbol{X}_{n_{p}}\right)
\end{array}\right]
\end{aligned}
\end{aligned}
$$

ただし，Iは $n_{p} \times n_{p}$ の単位行列, $\lambda$ は微小な正の定数であり, 本研究では $\lambda=1.0 \times 10^{-2}$ とした. 


\section{4. 提案する信頼性に基づく大域的最適化手法}

\section{$4 \cdot 1$ 確定的な最適化問題への変換}

$j$ 番目の信頼性制約が満たされる場合を考える。このときの標準正規空間における MPP と目標の信頼性指標の 関係を図 2(a)に示寸.式(11)の関係より, 原点から MPP までの距離 $\beta_{j}$ と目標の信頼性指標 $\beta_{j}^{\mathrm{Tar}}$ の関係は $\beta_{j} \geq \beta_{j}^{\mathrm{Tar}}$ である. そこで，図 2(a)に示す MPTP（Most Probable Target Point）について考える.これは，原点を中心として半 径を $\beta_{j}^{\mathrm{Tar}}$ とする超球面上で限界状態関数の值が最小となる点であり, 以下のように定義される.

$$
\boldsymbol{u}_{\mathrm{MPTP}}^{(j)}=\arg \min _{\|\boldsymbol{u}\|=\beta_{j}^{\mathrm{Tar}}} g_{j}^{U}(\boldsymbol{u})
$$

MPTP は安全領域に含まれるため，信頼性制約はMPTP を用いた制約 $g_{j}^{U}\left(\boldsymbol{u}_{M P T P}^{(j)}\right) \geq 0$ に置き換えられる.

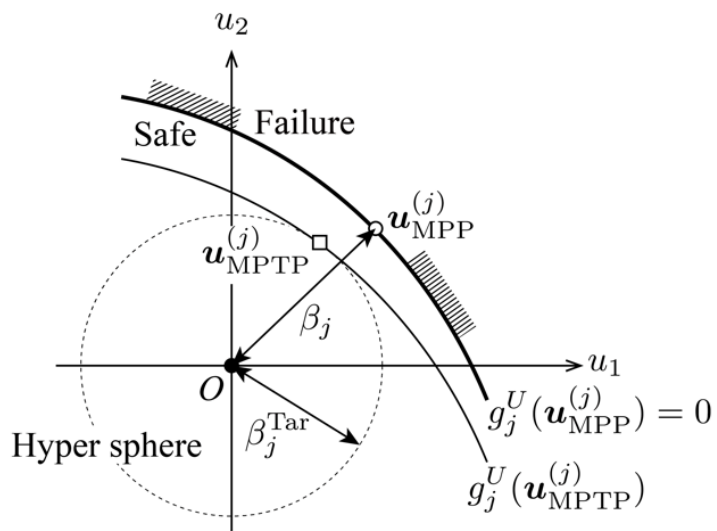

(a) MPP and MPTP

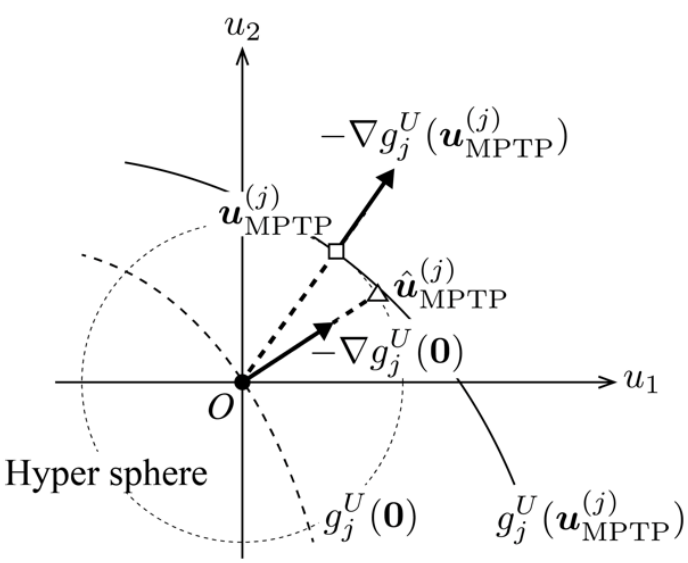

(b) Approximated MPTP

Fig. 2 MPP, MPTP, and approximated MPTP in the standard normal space.

次に，MPTP の導出方法について考える．図 2(b)に示すように，MPTP の位置ベクトルが MPTP における限界 状態関数の最急降下方向となる性質を利用すると, 以下の関係が成り立つ.

$$
\boldsymbol{u}_{\mathrm{MPTP}}^{(j)}=-\beta_{j}^{T a r} \frac{\nabla g_{j}^{U}\left(\boldsymbol{u}_{\mathrm{MPTP}}^{(j)}\right)}{\left\|\nabla g_{j}^{U}\left(\boldsymbol{u}_{\mathrm{MPTP}}^{(j)}\right)\right\|}
$$

両辺に $\boldsymbol{u}_{\mathrm{MPTP}}^{(j)}$ があることから，繰り返し計算を利用して MPTP を評価する必要がある，そこで，式(17)中の勾 配ベクトルを原点における勾配ベクトルに置き換えることで以下の式が得られる.

$$
\boldsymbol{u}_{\mathrm{MPTP}}^{(j)} \approx-\beta_{j}^{T a r} \frac{\nabla g_{j}^{U}(\mathbf{0})}{\left\|\nabla g_{j}^{U}(\mathbf{0})\right\|}
$$

また，原点における勾配は，設計空間における限界状態関数の勾配を用いて，

$$
\frac{\partial g_{j}^{U}(\mathbf{0})}{\partial u_{i}}=\left.\frac{\partial g_{j}(\boldsymbol{d})}{\partial x_{i}} \cdot \frac{\partial x_{i}}{\partial u_{i}}\right|_{\boldsymbol{x}=\boldsymbol{d}}
$$


と表される. 式(19)右辺の第 1 項は設計変数ベクトルdにおける限界状態関数の勾配, 第2 項は式(4)の関係から得 られる勾配である. 以上から， MPTP は設計変数べクトルの情報のみから近似できる. よって，式(1)で示した信 頼性に基づく最適設計問題は, 以下の確定的な最適設計問題に変換できる.

Minimize: $f(\boldsymbol{d})$

subject to: $g_{j}^{U}\left(\widehat{\boldsymbol{u}}_{\mathrm{MPTP}}^{(j)}\right)=g_{j}\left(\hat{\boldsymbol{x}}_{\mathrm{MPTP}}^{(j)}\right) \geq 0 \quad(j=1, \cdots, m)$

$$
d_{i}^{L} \leq d_{i} \leq d_{i}^{U} \quad(i=1, \cdots, n)
$$

ただし, $\widehat{\boldsymbol{u}}_{\mathrm{MPTP}}^{(j)}=T_{r}\left(\hat{\boldsymbol{x}}_{\mathrm{MPTP}}^{(j)}\right)$ は式(18)と式(19)を用いて得られる MPTP の近似值である. なお, MPTP が複数 考えられる場合でも，限界状態関数の值は同じであることから最適化結果に影響はない.

【例題】以下に示寸信頼性に基づく最適設計問題を考える.

Minimize: $f(\boldsymbol{d})=10-d_{1}+d_{2}$

subject to: $P\left[g_{j}(\boldsymbol{x}) \leq 0\right] \leq \Phi\left(-\beta_{j}^{\text {Tar }}\right) \quad(j=1,2,3)$

$$
0 \leq d_{i} \leq 10 \quad(i=1,2)
$$

where: $\quad g_{1}(\boldsymbol{x})=\frac{x_{1}^{2} x_{2}}{20}-1$,

$$
\begin{aligned}
& g_{2}(\boldsymbol{x})=\frac{\left(x_{1}+x_{2}-5\right)^{2}}{30}+\frac{\left(x_{1}-x_{2}-12\right)^{2}}{120}-1, \\
& g_{3}(\boldsymbol{x})=\frac{80}{x_{1}^{2}+8 x_{2}+5}-1,
\end{aligned}
$$

ただし，目標の信頼性指標を全て 3 とし，確率変数は互いに独立な正規分布に従い，その標準偏差を 0.3 とす る.このとき，標準正規確率変数への変換は，

$$
u_{i}=\frac{x_{i}-d_{i}}{\sigma_{i}}=\frac{x_{i}-d_{i}}{0.3} \quad(i=1,2)
$$

となるので，勾配は以下のように求められる.

$$
\frac{\partial x_{i}}{\partial u_{i}}=0.3 \quad(i=1,2)
$$

ここで， $g_{1}(\boldsymbol{x})$ につて考える. 式(19)を用いて標準正規空間における勾配べクトルを求めると,

$$
\nabla g_{1}^{U}(\mathbf{0})=\left(\frac{3 d_{1} d_{2}}{100}, \frac{3 d_{1}^{2}}{200}\right)^{T}
$$

となるので，式(18)から MPTP の近似値は次のように求められる.

$$
\boldsymbol{u}_{M P T P}^{(1)}=\left(\frac{-6 d_{1} d_{2}}{\sqrt{4 d_{1}^{2} d_{2}^{2}+d_{1}^{4}}}, \frac{-3 d_{1}^{2}}{\sqrt{4 d_{1}^{2} d_{2}^{2}+d_{1}^{4}}}\right)^{T}
$$

ここで，式(21)の関係を用いて，MPTP の近似值を設計変数空間に変換すると，

$$
\widehat{\boldsymbol{x}}_{\mathrm{MPTP}}^{(1)}=\boldsymbol{d}+0.3 \widehat{\boldsymbol{u}}_{\mathrm{MPTP}}^{(1)}
$$


となるので, 確定的な最適設計問題の制約 $g_{1}\left(\hat{\boldsymbol{x}}_{\mathrm{MPTP}}^{(1)}\right)$ は設計変数を用いて評価ができる.このようにして得られ た限界状態関数に対寸る実行可能領域 $g_{j}\left(\widehat{\boldsymbol{x}}_{\mathrm{MPTP}}^{(j)}\right) \geq 0(j=1,2,3)$ と, 確定的な最適設計問題を解いて得られた 最適解を図 3 に示寸. この図から, 実行可能領域は限界状態 $g_{j}(\boldsymbol{x})=0(j=1,2,3)$ で囲まれる領域よりも安全側 にあることがわかる.さらに，得られた最適解 $(5.85,3.42)^{T}$ における信頼性指標を MCS（サンプル数 $10^{7}$ ) で評価 すると, $\beta_{1}=$ inf, $\beta_{2}=3.02, \beta_{3}=2.99$ となり, 信頼性制約をおおよそ満足している. よって, 式(20)で示した 確定的な最適設計問題を解くことで，信頼性に基づく最適設計問題の最適解が得られることがわかる.

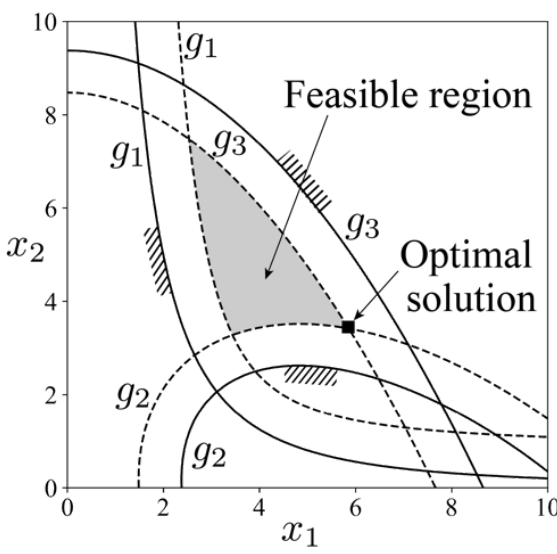

$$
\begin{aligned}
& -g_{j}(\boldsymbol{x})=0 \\
& --g_{j}\left(\hat{\boldsymbol{x}}_{\mathrm{MPTP}}^{(j)}\right)=0
\end{aligned}
$$

Fig. 3 Deterministic RBDO: limit state functions, feasible region, and optimal solution.

\section{4-2 サンプル点の追加方法}

\section{$4 \cdot 2 \cdot 1$ 密度関数を利用した追加}

大域的な様相を把握寸るためには，サンプル点が疎な領域を見つけ，そこにサンプル点を追加することでサン プル点をなるべく一様に配置することが有効と考えられる．本研究では，著者の一人が提案した密度関数を利用 する方法を採用する (Kiatayam et al., 2011). 以下に，その概要を説明する.

訓練データ $\boldsymbol{X}_{k}$ に対応する教師データを $Y_{k}\left(1, \cdots, n_{p}\right)$ とする. このサンプル点を RBF ネットワークによって学 習することで作成される応答曲面 $D(\boldsymbol{X})$ を密度関数とよび，以下のように表される.

$$
\begin{aligned}
& D(\boldsymbol{X})=\sum_{k=1}^{n_{p}} w^{D}{ }_{k} h_{k}(\boldsymbol{X}) \\
& \text { where: } \boldsymbol{w}^{D}=\left(\boldsymbol{H}^{T} \boldsymbol{H}+\boldsymbol{\Lambda}\right)^{-1} \boldsymbol{H}^{T} \boldsymbol{Y}^{D} \text {, } \\
& \boldsymbol{w}^{D}=\left(w_{1}^{D}, \cdots, w_{n_{p}}^{D}\right)^{T}, \\
& \boldsymbol{Y}^{D}=(1, \cdots, 1)^{T}
\end{aligned}
$$

密度関数は, 教師データが全て 1 であることから, サンプル点間の距離のみでその応答值が決まる. つまり, 密度関数の值が小さいほど既存のサンプル点から離れていると考えられる. そのため, 密度関数を最小化する点 をサンプル点として追加することで，サンプル点の疎な領域への追加が期待できる.

\section{4 - 2 - 2 MPTP への追加}

本研究では, 式(20)で示した確定的な最適設計問題を考えるため, MPTPにおける限界状態関数の值 $g_{j}\left(\hat{\boldsymbol{x}}_{\mathrm{MPTP}}^{(j)}\right)$ を高い精度で近似することが重要である．そのため，MPTP をサンプル点として追加することは妥当と考えられ る. さらに, 最適解における MPTP を追加すれば, 最適解周辺における応答曲面の局所的な近似精度の向上が期 待できる. しかし, 限界状態関数の数だけ MPTP は存在するため, 限界状態関数の数が増加するにつれて追加す るサンプル点数も増加し, 効率的とは言い難い. そこで, 最適解でのアクティブな限界状態関数の中で MPTP に おける応答曲面の近似精度を比較し, 最も近似精度が低い MPTP を追加サンプル点とする. 
しかし，応答曲面の近似精度は，実際にサンプル点として追加し，教師データを得ない限り評価できない，そ こで, サンプル点の配置から応答曲面の近似精度を予測することにする. つまり, 既存のサンプル点付近に MPTP が位置する場合は, MPTP における近似精度が高く, 離れた位置にある場合は近似精度が低いと考える. そして, 既存のサンプル点と MPTP の位置関係を密度関数の值 $D\left(\hat{\boldsymbol{x}}_{\mathrm{MPTP}}^{(j)}\right)$ で評価することにする. 密度関数はサンプル 点間の距離を反映しているため, 密度関数が最小となる MPTP は既存のサンプル点から最も離れた近似精度の低 い点と考えることができる. また, 応答曲面の近似精度は関数の性質にも依存するため, 密度関数の值が高い場 合でも近似精度が低いことが考えられる. しかし, 逐次的にサンプル点を追加していくことで近似精度は次第に 向上していくと考えられることから, 得られる最適解への影響は少ない. 以上から, アクティブな限界状態関数 でかつ， $\widehat{x}_{\mathrm{MPTP}}$ における密度関数の值が最小となる点をサンプル点として追加する.

【例題】再び式(21)で示した信頼性に基づく最適設計問題を用いて応答曲面の近似精度を密度関数の值を比較 することで判断する方法の妥当性について検証する. ここでは, サンプル点を配置して応答曲面を作成し, 確定 的な最適設計問題に置き換えて最適解を得た状態を考える. その様子を図 4(a)に示す．なお，応答曲面で近似し た目的関数と限界状態関数をそれぞれ $\hat{f}(\cdot), \hat{g}_{j}(\cdot)$ と表記する.

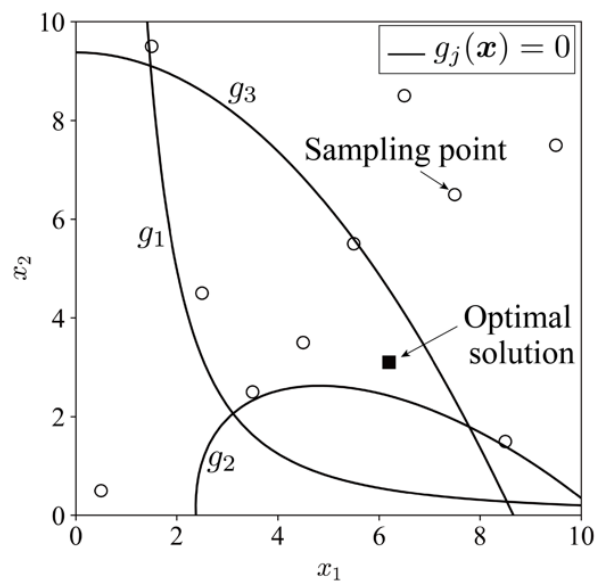

(a) Distribution of sampling points and optimal solution

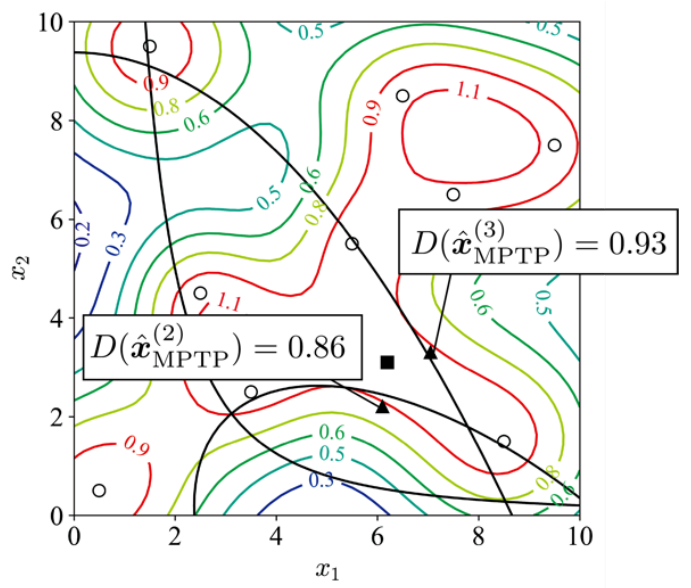

(b) Contour of density function

Fig. 4 Comparing approximation accuracy at each MPTP with density function.

得られた最適解において，アクティブな限界状態関数は $\hat{g}_{2}(\boldsymbol{x}), \hat{g}_{3}(\boldsymbol{x})$ である. どの MPTP を追加サンプル点と するかを判断するため, 配置したサンプル点と最適解の位置を訓練データとして密度関数を構築する. 構築した 密度関数の等高線を図 4(b)に示す.この図より, $\hat{g}_{2}(\boldsymbol{x})$ に対応する MPTP の密度関数の值の方が小さいことがわか るので, $\hat{g}_{2}(\boldsymbol{x})$ の近似精度も低いと予想できる. そこで, アクティブな限界状態関数 $\hat{g}_{2}(\boldsymbol{x}), \hat{g}_{3}(\boldsymbol{x})$ に対応する MPTP における近似精度を相対誤差で評価すると, それぞれ $100 \%$ と $2.6 \%$ となり, 先ほどの予想は正しいとわかった. 以上から, 応答曲面の近似精度を密度関数の值を比較することで判断する方法は妥当であると考えられる.

\section{$4 \cdot 3$ 提案手法の計算手順}

図 5 に, 提案手法のフローチャートを示寸. また, 以下に計算手順を示寸.

1. 初期サンプル点を配置する. 最大サンプル数 $n_{\max }$ を決める.

2. 配置されたサンプル点から RBF ネットワークを用いて目的関数と限界状態関数の応答曲面を構築する.

3. 以下の確定的な最適設計問題を解き, 最適解をサンプル点に加える.

Minimize: $\hat{f}(\boldsymbol{d})$

subject to: $\hat{g}_{j}\left(\hat{\boldsymbol{x}}_{\mathrm{MPTP}}^{(j)}\right) \quad(j=1, \cdots, m)$

$$
d_{i}^{L} \leq d_{i} \leq d_{i}^{U} \quad(i=1, \cdots, n)
$$


4. サンプル数が最大サンプル数を超えていれば終了．そうでなければ，5. に進む.

5. 密度関数を利用してサンプル点を追加する.

5.1 密度関数を式(27)から構築する.

5.2 密度関数によるサンプル点の追加数が $n / 2$ を超えれば終了.そうでなければ， 5.3 に進む.

5.3 密度関数を最小化する点を探索し，サンプル点として追加する.

6. 密度関数の值が最小となる MPTP を追加サンプル点とする.

6.1 アクティブな限界状態関数に対して, それぞれの MPTP を式(18)と式(19)から求める

6.2 MPTP における密度関数の值を評価し，最小值をとる MPTP をサンプル点として追加する.

7. 2. 八戻る.

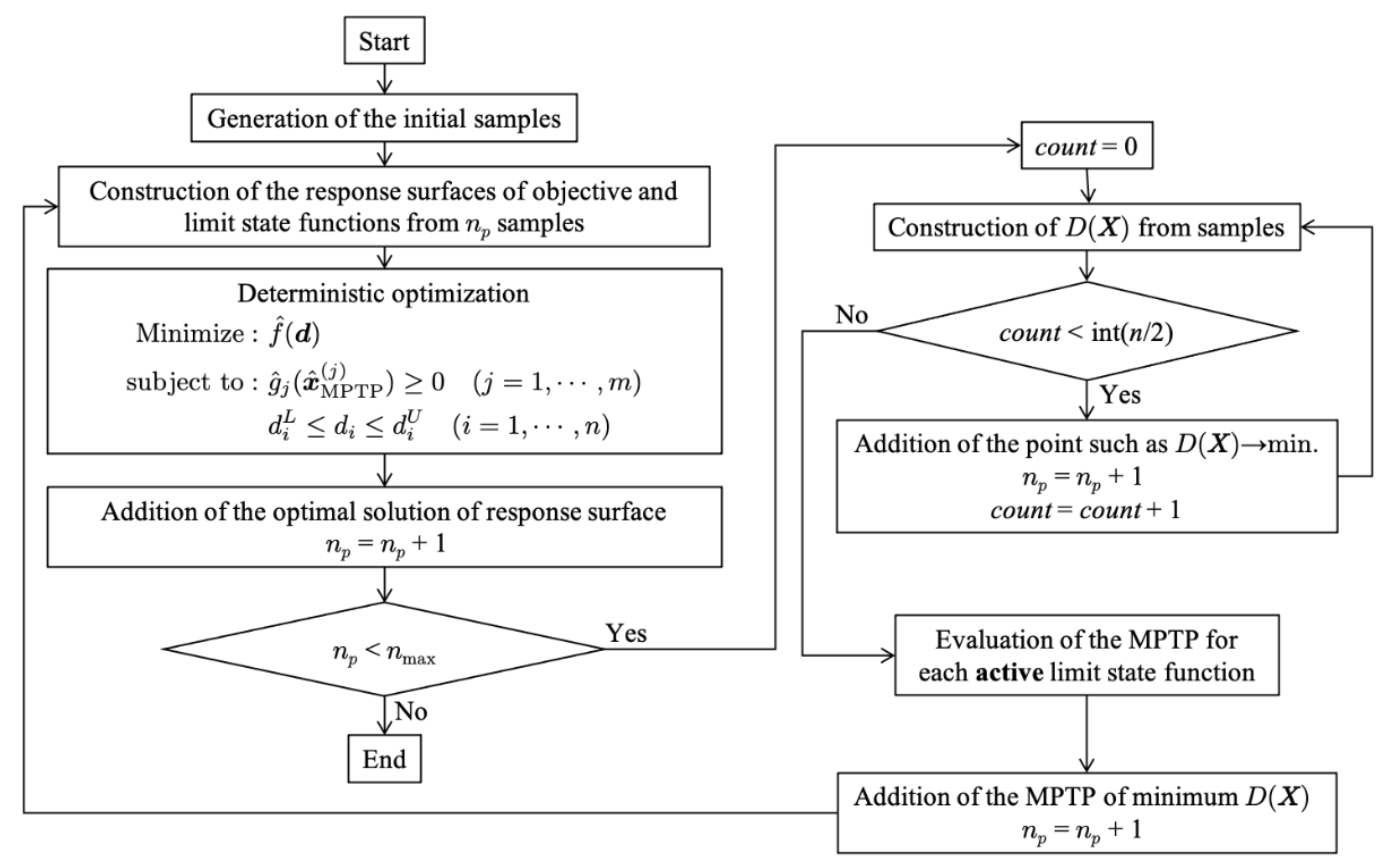

Fig. 5 Flow of proposed method.

\section{5. 数值計算例}

本章では，数值計算例を通して提案手法の有効性を検証する。本研究では，大域的最適解を探索するための多 点同時探索手法として，DE（Differential Evolution）を利用した.

\section{1 数值計算例 1: Modified-Haupt problem（複数の局所最適解を持つベンチマーク問題）}

以下に示す 2 次元の信頼性に基づく最適設計問題を考える.

Minimize: $f(\boldsymbol{d})=\left(d_{1}-3.7\right)^{2}+\left(d_{2}-4\right)^{2}$

subject to: $P\left[g_{j}(\boldsymbol{x}) \leq 0\right] \leq \Phi\left(-\beta_{j}^{\text {Tar }}\right) \quad(j=1,2,3)$

$0 \leq d_{1} \leq 3.7$

$0 \leq d_{2} \leq 4$

where: $g_{1}(\boldsymbol{x})=-x_{1} \sin \left(4 x_{1}\right)-1.1 x_{2} \sin \left(2 x_{2}\right)$

$$
g_{2}(\boldsymbol{x})=\left(x_{1}-2\right)^{2}+\left(x_{2}-2.5\right)^{2}-0.3
$$

ただし，目標の信頼性指標を全て 2 とし，確率変数は互いに独立な正規分布に従い，標準偏差は全て 0.1 でる.

この問題の目的関数の等高線, 限界状態関数ならびに最適解を図 6 に示す. 問題の特徵として, 実行可能領域 が分離しており, 局所最適解 2 つ大域的最適解が存在するため, 初期点を適切に設定しなけれげ大域的最適解 を探索できないことが知られている. 表 1 に 3 つの最適解の值を示す. 


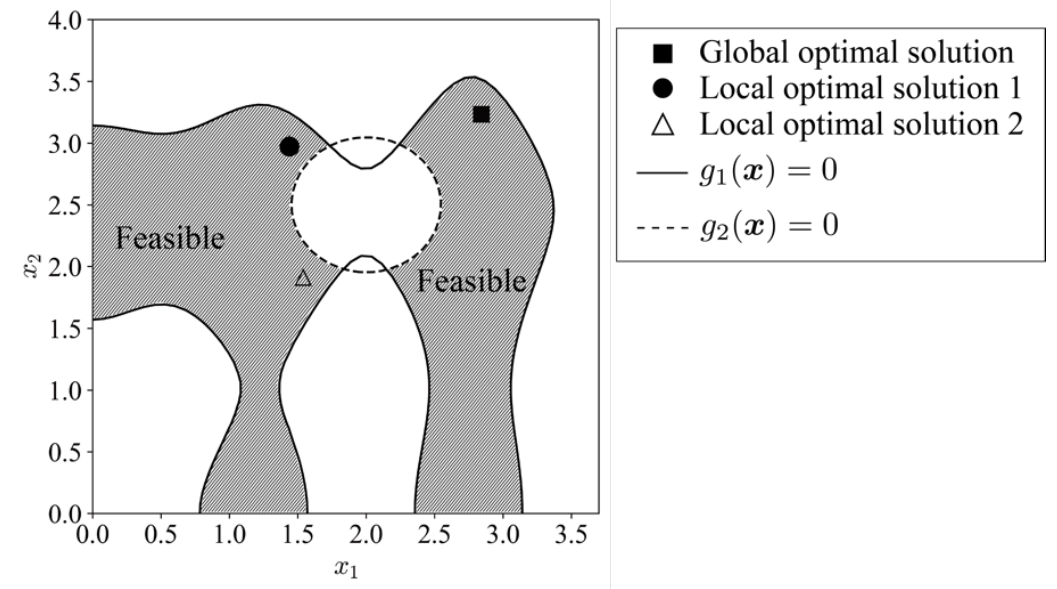

Fig. 6 Numerical example 1: contour of objective function, limit state functions, and optimal solutions.

Table 1 Global and local optimal solutions.

\begin{tabular}{l|cc|c}
\hline \hline & $d_{1}$ & $d_{2}$ & Objective \\
\hline Global optimal solution & 2.8421 & 3.2320 & 1.3259 \\
Local optimal solution 1 & 1.4374 & 2.9925 & 6.1342 \\
Local optimal solution 2 & 1.5393 & 1.9111 & 9.0323 \\
\hline
\end{tabular}

この問題に対して, LHS（Latin Hypercube Sampling）による初期サンプル点数を 10, 最大サンプル点数を 20 と して最適解を探索した．なお，初期サンプル点数と最大サンプル点数は先行研究 (Liu et al., 2017) (Liu et al., 2018) を参考に設定した．また，初期サンプル点配置への依存性を確認するため, 10 種類の異なる配置に対してそれぞ れ最適化を行い, その平均を先行研究での結果と比較した，その結果を表 2 に示す．ただし，信頼性指標は MCS

(サンプル数 $10^{7}$ ) で評価した. 表 2 より, 先行研究と同程度のサンプル数で, 大域的最適解が得られていること がわかる．さらに，標準偏差が小さいことから，初期サンプル点配置への依存も小さいと考えられる.

Table 2 Optimization results comparing with previous studies in numerical example 1.

\begin{tabular}{l|cc|c|c|cc}
\hline \hline & $d_{1}$ & $d_{2}$ & Objective & Sample & $\beta_{1}$ & $\beta_{2}$ \\
\hline $\begin{array}{l}\text { LR-RBDO } \\
\text { (Liu et al., 2017) }\end{array}$ & 2.8236 & 3.2687 & 1.3030 & 22 & 1.961 & 4.374 \\
\hline $\begin{array}{l}\text { AS-RBDO } \\
\text { (Liu et al., 2018) }\end{array}$ & 2.8239 & 3.2692 & 1.3018 & 19 & 1.870 & inf \\
\hline $\begin{array}{l}\text { This study } \\
\text { (Standard deviation) }\end{array}$ & $\begin{array}{c}2.9284 \\
(0.04)\end{array}$ & $\begin{array}{c}3.1139 \\
(0.07)\end{array}$ & $\begin{array}{c}1.3867 \\
(0.07)\end{array}$ & 22 & $\begin{array}{c}1.947 \\
(0.14)\end{array}$ & $\begin{array}{c}\text { inf } \\
(-)\end{array}$ \\
\hline
\end{tabular}

図 7 に，最終的なサンプル点配置の様子を示す。図 7 の網目部分は確定的な最適設計問題に変換した際の実行 可能領域を表している. 追加サンプル点に注目すると，得られた大域的最適解の周辺，特に限界状態上に追加サ ンプル点が集中していることが拡大図からわかる。ここで, 得られた大域的最適解のアクティブな限界状態関数 $g_{1}(\boldsymbol{x})$ に対応する MPTP の近似精度を相対誤差で評価したところ, 3.3\%となった. これは, MPTP に集中的に追加 したサンプル点によって，近似精度が向上した結果と考えられる，さらに，定性的ではあるが，追加サンプル点 の一部は大域的最適解と離れた場所にあり，設計空間全体にサンプル点を配置できている．これにより，実行可 能領域が分離しているというこの問題の大域的な様相も捉えられていると考えられる. 


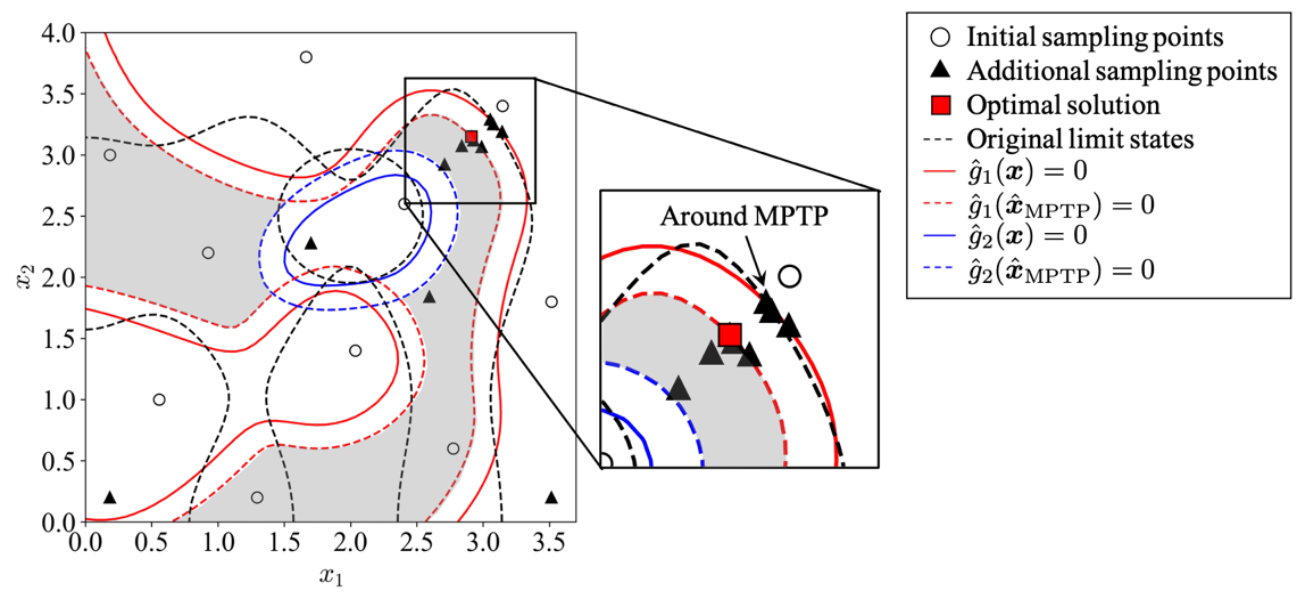

Fig. 7 Distribution of samples, global optimum, and approximated feasible region.

\section{$5 \cdot 2$ 数值計算例 2: Welded-beam problem（エ学的なベンチマーク問題）}

図 8 に示す片持ちはりの溶接部の設計を考える.

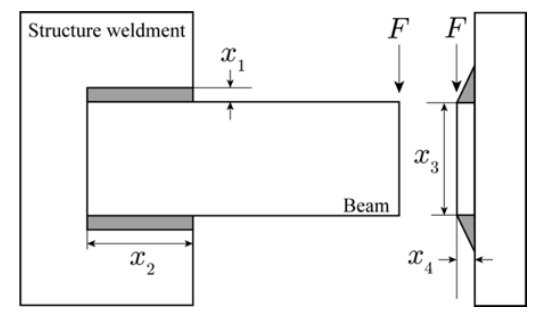

Fig. 8 Welded-beam problem.

溶接コストを最小化しつつ, 破損確率の制約を考慮して 4 つの寸法の期待值 $\boldsymbol{d}$ 決定する問題となっており, 以下のように定式化される.

$$
\begin{array}{ll}
\text { Minimize: } & f(\boldsymbol{d})=c_{1} d_{1}^{2} d_{2}+c_{2} d_{3} d_{4}\left(z_{2}+d_{2}\right) \\
\text { subject to: } & P\left[g_{j}(\boldsymbol{x}) \leq 0\right] \leq \Phi\left(-\beta_{j}^{T a r}\right) \quad(j=1, \cdots, 5) \\
& d_{i}^{L} \leq d_{i} \leq d_{i}^{U}(i=1, \cdots, 4) \\
\text { where: } \quad & g_{1}(\boldsymbol{x})=1-\frac{\tau(\boldsymbol{x})}{z_{6}}, \\
g_{2}(\boldsymbol{x})=1-\frac{\sigma(\boldsymbol{x})}{z_{7}}, & \\
g_{3}(\boldsymbol{x})=1-\frac{x_{1}}{x_{4}} & \\
g_{4}(\boldsymbol{x})=1-\frac{\delta(\boldsymbol{x})}{z_{5}} & \\
g_{5}(\boldsymbol{x})=\frac{P_{c}(\boldsymbol{x})}{z_{1}}-1
\end{array}
$$

ただし, 目標の信頼性指標を全て 3 とし，確率変数は互いに独立な正規分布に従うものとする．確率変数の標 準偏差と設計変数の側面制約を表 3 に示寸. また, 式(30a)の目的関数において, $c_{1}, c_{2}$ は溶接作業コストと材料コ ストのパラメータである. また, 限界状態関数内の $\tau(\boldsymbol{x}), \sigma(\boldsymbol{x}), \delta(\boldsymbol{x}), P_{c}(\boldsymbol{x})$ は, それぞれ最大せん断応力, 最大 垂直応力, 先端変位, 座屈荷重で, パラメータ $\boldsymbol{z}=\left(z_{1}, \cdots, z_{7}\right)^{T}$ から評価できる. パラメータの值を表 4 に示す. 
Table 3 Boundary constraints and standard deviation of each length in numerical example 2.

\begin{tabular}{c|cccc}
\hline \hline$i$ & 1 & 2 & 3 & 4 \\
\hline$d_{i}^{L}[\mathrm{~mm}]$ & 3.175 & 0 & 0 & 0 \\
$d_{i}^{U}[\mathrm{~mm}]$ & 50.8 & 254 & 254 & 50.8 \\
Standard deviation & 0.1693 & 0.1693 & 0.0107 & 0.0107 \\
\hline
\end{tabular}

Table 4 Parameters in numerical example 2.

\begin{tabular}{l|l|l}
\hline \hline Parameters & Value & Property \\
\hline$c_{1}\left[\$ / \mathrm{mm}^{3}\right]$ & $6.74135 \cdot 10^{-5}$ & Welding cost \\
$c_{2}\left[\$ / \mathrm{mm}^{3}\right]$ & $2.93585 \cdot 10^{-6}$ & Material cost \\
$z_{1}[\mathrm{~N}]$ & $2.6688 \cdot 10^{4}$ & Load $(\mathrm{F})$ \\
$z_{2}[\mathrm{~mm}]$ & $3.556 \cdot 10^{2}$ & Length of cantilever \\
$z_{3}[\mathrm{MPa}]$ & $2.0685 \cdot 10^{5}$ & Young's modulus \\
$z_{4}[\mathrm{Mpa}]$ & $8.274 \cdot 10^{4}$ & Shear modulus \\
$z_{5}[\mathrm{~mm}]$ & 6.35 & Tolerance of tip displacement \\
$z_{6}[\mathrm{Mpa}]$ & $9.377 \cdot 10^{1}$ & Tolerance of shearing stress \\
$z_{7}[\mathrm{Mpa}]$ & $2.0685 \cdot 10^{2}$ & Tolerance of normal stress \\
\hline
\end{tabular}

この問題に対して, LHS を用いて初期サンプル点を 30 点配置し, 最大サンプル点数を 60 として最適解を探索 した. なお，初期サンプル点数と最大サンプル点数は先行研究(Ju and Lee, 2008) (Meng et al., 2019)を参考に設定 した。その結果を表 5 に示す. 表 5 中の PMA（Performance Measure Approach）（Tu and Choi, 1999）は，関数形を 既知として探索した結果である. なお，信頼性指標はMCS（サンプル数 $10^{7}$ ) で評価した.

Table 5 Optimization results comparing with previous studies in numerical example 2.

(a) Optimal solutions, objective function value and number of samples

\begin{tabular}{l|cccc|c|c}
\hline \hline & $d_{1}$ & $d_{2}$ & $d_{3}$ & $d_{4}$ & Objective & Sample \\
\hline PMA & 5.730 & 200.898 & 210.598 & 6.239 & 2.5913 & - \\
\hline $\begin{array}{l}\text { Moment-based RBDO } \\
\text { (Ju and Lee, 2008) }\end{array}$ & 5.730 & 200.602 & 210.598 & 6.239 & 2.5895 & 341 \\
\hline $\begin{array}{l}\text { AK-ACSLA } \\
\text { (Meng et al., 2019) }\end{array}$ & 5.731 & 200.665 & 210.615 & 6.237 & 2.5893 & 66 \\
\hline This study & 5.855 & 197.747 & 210.610 & 6.441 & 2.6506 & 62 \\
\hline
\end{tabular}

(b) Reliability index

\begin{tabular}{l|ccccc}
\hline \hline & $\beta_{1}$ & $\beta_{2}$ & $\beta_{3}$ & $\beta_{4}$ & $\beta_{5}$ \\
\hline PMA & 2.999 & 3.007 & 3.002 & inf & 3.005 \\
\hline $\begin{array}{l}\text { Moment-based RBDO } \\
\text { (Ju and Lee, 2008) }\end{array}$ & 2.981 & 2.912 & 2.983 & inf & 2.828 \\
\hline $\begin{array}{l}\text { AK-ACSLA } \\
\text { (Meng et al., 2019) }\end{array}$ & 2.965 & 3.007 & 3.002 & inf & 3.005 \\
\hline \begin{tabular}{l} 
This study \\
\hline
\end{tabular} & 3.381 & inf & 3.278 & inf & inf \\
\hline
\end{tabular}


表 5 から, 提案手法は比較的少ないサンプル数で先行研究と同様に大域的最適解を得られているとわかる. ま た，関数形を既知として探索した PMA ともおおよそ一致する結果となっている. この結果から，提案手法の有 効性の一端が示された. サンプル点数が比較的少ない理由として, 大域的な様相を把握しながら最適解を探索す るため, 大域的最適解の周辺を早く見つけられる可能性があること, そして局所的な近似精度向上のために複数 のサンプル点を追加しないことが考えられる.

\section{$5 \cdot 3$ 数値計算例 3: 変位拡大機構の設計問題}

図 9 に示すコンプライアントメカニズム化された変位拡大機構の設計問題を考える（Ito et al., 2018）.

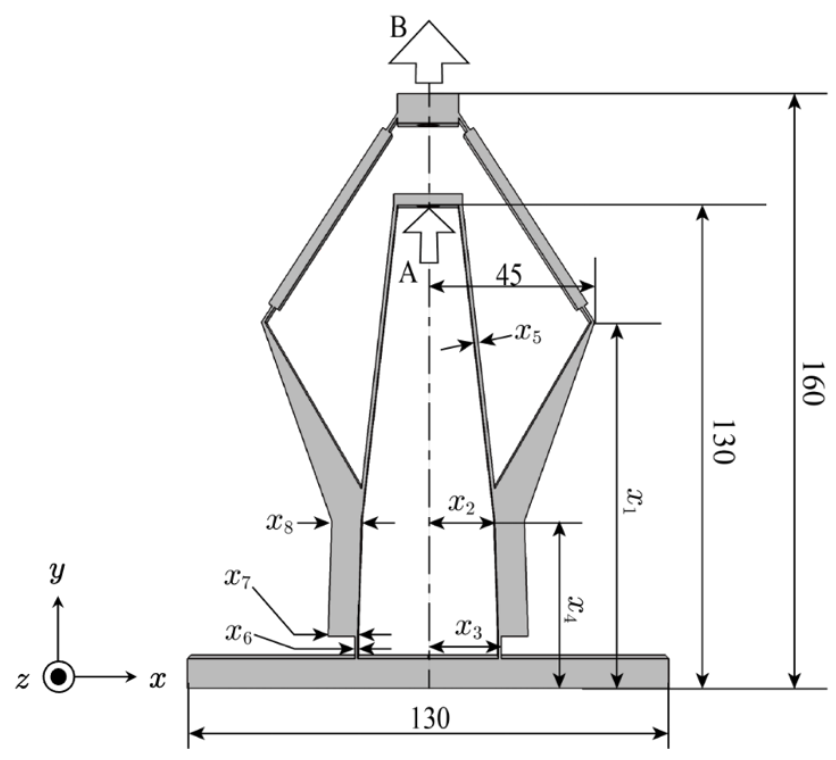

Fig. 9 Displacement amplifier design problem (unit: [mm]).

この変位拡大機構は，形状可変鏡と呼ばれる軌道上で鏡面形状を制御するアンテナシステムに搭載することを 目的に研究開発が進められている．ここでは，底部を完全固定して入力部 A に $0.1 \mathrm{~mm}$ の強制変位を加えたとき に, 出力部 B に生じる出力変位を最大化することを目的とする. また, 変位拡大機構の破損はアンテナシステム 全体に深刻な影響を及ぼすことから，最大応力に対して破損確率の制約を課す．確率変数べクトル $\boldsymbol{x}$ は，製作誤 差を不確定性としてモデル化した寸法であり, 設計変数dはその期待值とする. 以上から, 最適設計問題は次のよ うに定式化される。

Minimize: $f(\boldsymbol{d})=$ (output displacement)

subject to: $P[\mathrm{~g}(\boldsymbol{x}) \leq 0] \leq \Phi\left(-\beta^{\text {Tar }}\right)$

$$
d_{i}^{L} \leq d_{i} \leq d_{i}^{U}(i=1, \cdots, 8)
$$

where: $g(\boldsymbol{x})=300 \mathrm{MPa}-$ (Maximum stress)

ただし，目標の信頼性指標を 3 とし，確率変数は互いに独立な正規分布に従うものとする. 確率変数の標準偏 差と設計変数の側面制約を表 6 に示す．また，材料物性はヤング率 $167 \mathrm{GPa}$ ，ポアソン比 0.3 とした.

Table 6 Boundary constraints and standard deviation of each length in numerical example 3.

\begin{tabular}{c|cccccccc}
\hline \hline$i$ & 1 & 2 & 3 & 4 & 5 & 6 & 7 & 8 \\
\hline$d_{i}^{L} \quad[\mathrm{~mm}]$ & 85.0 & 18.0 & 18.0 & 45.0 & 0.5 & 0.5 & 2.0 & 2.0 \\
$d_{i}^{U} \quad[\mathrm{~mm}]$ & 125.0 & 25.0 & 25.0 & 80.0 & 1.5 & 2.0 & 8.0 & 8.0 \\
Standard deviation & 0.200 & 0.312 & 0.0722 & 0.0395 & 0.0204 & 0.0258 & 0.0729 & 0.231 \\
\hline
\end{tabular}


この問題に対して, LHS を用いて初期サンプル点を 30 点配置し，最大サンプル数を 65 として得られた最適解 を表 7 に示寸．なお，最大サンプル点数は構造解析にかかる時間を考慮して決定した．また，最適形状とその変 形図ならびに von Mises 応力のコンターを図 10 に示す. 図 10(b)に示すように, 最適形状の出力変位は $0.82 \mathrm{~mm}$ となった．変形図から，入力部が押し上げられて機構が内側に倒れ，柔軟ヒンジ (flexural hinge) が回転すること で, 変位が出力部で拡大される様子がわかる. また, 変形時にかかる最大応力は, $255.3 \mathrm{MPa}$ となった. このとき の信頼性指標を MCS（サンプル数 $10^{3}$ ) で評価すると 3.06 となり，信頼性制約を満たすことも示された. 図 10(c) に示寸ように, 変形時は, 比較的部材が薄く, 柔軟性が高い部材に高い応力が発生している. 一般的に, コンプ ライアントメカニズムでは，柔軟性の高い部分を設けることで変形量を大きくする一方で，その部分に応力が集 中して破損することが問題となる．しかし，今回得られた最適形状は，応力による破損に対して安全余裕が十分 確保されていること（ $(-\beta)=1.2 \%)$ から, アンテナシステムに搭載する変位拡大機構として望ましいといえ る.

Table 7 Optimization result in numerical example 3.

\begin{tabular}{c|cccccccc}
\hline \hline$i$ & 1 & 2 & 3 & 4 & 5 & 6 & 7 & 8 \\
\hline$d_{i}[\mathrm{~mm}]$ & 96.75 & 20.46 & 18.58 & 51.28 & 0.79 & 1.06 & 5.70 & 7.43 \\
\hline
\end{tabular}

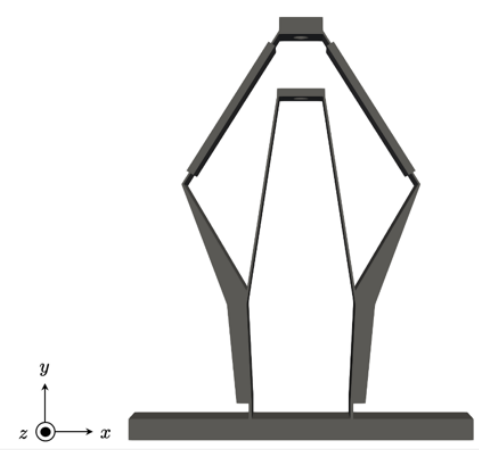

(a) Optimal configuration

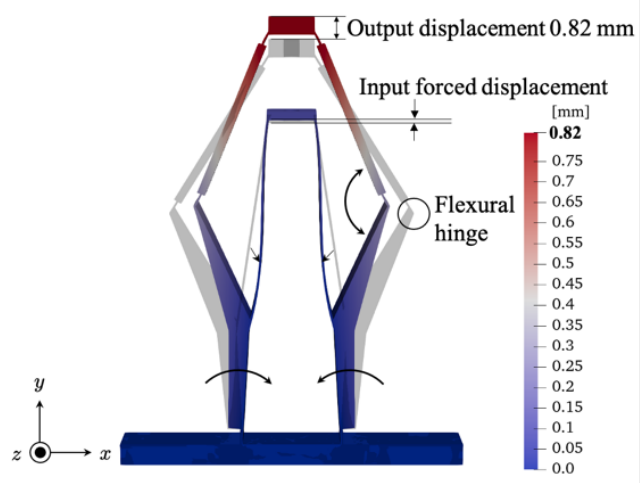

(b) Deformation

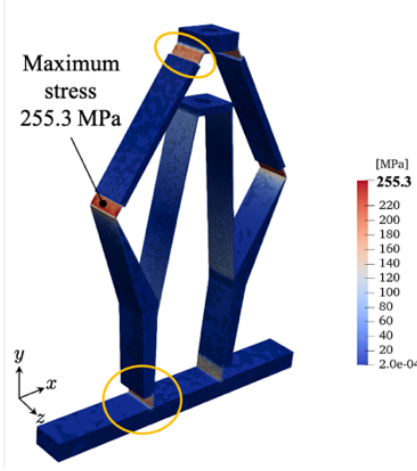

(c) von Mises stress

Fig. 10 Optimal configuration, deformation, and von Mises stress.

\section{6. 結 言}

本研究では, 応答曲面を利用した信頼性に基づく大域的最適化手法を提案した. 多点同時探索による大域的最 適解の探索を効率的に行うため, 信頼性に基づく最適設計問題を確定的な最適設計問題に変換し, 破損確率の評 価による二重ループを解消した．また，密度関数を利用してサンプル点の疎な領域に新たなサンプル点を追加す る方法と応答曲面の近似精度が低い MPTP を密度関数から判別して追加サンプル点とする方法を提案し, 大域的 な样相の把握と局所的な近似精度の向上を目指した. ベンチマーク問題を通して提案手法の有効性を検証し, 初 期サンプル点の配置に依存せずに大域的最適解を得られることを示した. 追加されたサンプル点によって, 大域 的様相の把握と局所的な近似精度の向上が可能であることを確認した. 工学的なベンチマーク問題と変位拡大機 構の設計問題を通して, 提案手法の工学問題への適用可能性を示した. また, 本研究で扱った数値計算例の範囲 内で，提案手法は少ないサンプル点数で大域的最適解を探索する上で有効であるとわかった.

\section{謝 辞}

本研究は, JSPS 科研費 JP20K14637 の助成を受けたものである. 


\section{References}

Chen, Z., Qiu, H., Gao, L., Li, X. and Li, P., A local adaptive sampling method for reliability-based design optimization using kriging model. Structural and Multidisciplinary Optimization, Vol. 49, No. 3 (2014), pp. 401-416.

Chen, Z., Peng, S., Li, X., Qiu, H., Xiong, H., Gao, L. and Li, P., An important boundary sampling method for reliability-based design optimization using kriging model, Structural and Multidisciplinary Optimization, Vol. 52, No. 1 (2015), pp. 55-70.

Choi, S. K., Grandhi, R. V. and Canfield, R. A., Reliability-based Structural Design, Springer-Verlag London (2007).

Dubourg, V., Sudret, B. and Bourinet, J. M., Reliability-based design optimization using kriging surrogates and subset simulation, Structural and Multidisciplinary Optimization, Vol. 44, No. 5 (2011), pp. 673-690.

Hu, W., Choi, K. K. and Cho, H., Reliability-based design optimization of wind turbine blades for fatigue life under dynamic wind load uncertainty, Structural and Multidisciplinary Optimization, Vol. 54 (2016), pp. 953-970.

Ito, M., Kim, N. H. and Kogiso, N., Conservative reliability index for epistemic uncertainty in reliability-based design optimization, Structural and Multidisciplinary Optimization, Vol. 57 (2018), pp. 1919-1935.

Jones, D., Schonlau, M. and Welch, W., Efficient global optimization of expensive black-box functions, Journal of Global Optimization, Vol. 13 (1998), pp. 455-492.

Ju, B. H. and Lee, B. C., Reliability-based design optimization using a moment method and a kriging metamodel, Engineering Optimization, Vol. 40, No. 5 (2008), pp. 421-438.

Kitayama, S., Arakawa, M. and Yamazaki, K. Sequential Approximate Optimization using Radial Basis Function network for engineering optimization. Optimization and Engineering, Vol. 12 (2011), pp. 535-557.

Lee, T. H. and Jung, J. J., A sampling technique enhancing accuracy and efficiency of metamodel-based RBDO: Constraint boundary sampling, Computers and Structures, Vol. 86, No. 13-14 (2008), pp. 1463-1476.

Li, X., Qiu, H., Chen, Z., Gao, L. and Shao, X., A local Kriging approximation method using MPP for reliability-based design optimization, Computers and Structures, Vol. 162, No. 1 (2016), pp. 102-115.

Liu, X., Wu, Y., Wang, B., Ding, J. and Jie, H., An adaptive local range sampling method for reliability-based design optimization using support vector machine and Kriging model, Structural and Multidisciplinary Optimization, Vol. 55, No. 6 (2017), pp. 2285-2304.

Liu, X., Wu, Y., Wang, B., Yin, Q. and Zhao, J., An efficient RBDO process using adaptive initial point updating method based on sigmoid function, Structural and Multidisciplinary Optimization, Vol. 58, No. 6 (2018), pp. 2583-2599

Meng, Z., Zhang, Z., Zhang, D. and Yang, D., An active learning method combining kriging and accelerated chaotic single loop approach (AK-ACSLA) for reliability-based de-sign optimization. Computer Methods in Applied Mechanics and Engineering, Vol. 357 (2019), DOI: 10.1016/j.cma.2019.112570.

Tu, J. and Choi, K. K., A New Study on Reliability Based Design Optimization, Journal of Mechanical Design, Vol. 121, No. 4 (1999), pp. 557-564.

Youn, B. D., Choi, K. K. and Gu, L., Reliability-based design optimization for crashworthiness of vehicle side impact, Structural and Multidisciplinary Optimization, Vol. 26 (2004), pp. 272-283.

Youn, B. D. and Choi, K. K., A new response surface methodology for reliability-based design optimization, Computers and Structures, Vol. 82, No. 2-3 (2004), pp. 241-256.

Zhuang, X. and Pan, R., A sequential sampling strategy to improve reliability-based design optimization with implicit constraint functions, Journal of Mechanical Design, Vol. 134, No. 2 (2012), pp. 1-10. 